\title{
PRELIMINARY APPROACH FOR A PROTOTYPE OF SUSTAINABLE ANTISEISMIC DWELLING IN NEPAL BASED ON THE HISTORIC VERNACULAR TRADITION
}

\section{FERNANDO VEGAS LÓPEZ-MANZANARES ${ }^{{ }^{*}}$, CAMILLA MILETO ${ }^{1}$, WALTER PISARRA $^{1}$ AND FRANCESCA TRIZIO ${ }^{1}$}

\author{
${ }^{1}$ Universitat Politècnica de València (UPV) \\ IRP, Camino de Vera s/n, 46022 Valencia, Spain \\ e-mail: fvegas@cpa.upv.es ; ${ }^{*}$ cami2@cpa.upv.es; walter.pisarra@gmail, fratri@upvnet.upv.es
}

Keywords: Vernacular architecture, Rammed Earth, Pendentive dome, Antiseismic Structure

\begin{abstract}
The effects of the 2015 Gorkha earthquake in Nepal revealed deficiencies in the most recent vernacular architecture, which no longer uses wooden reinforcements due to national anti-deforestation laws. It also highlighted the shortcomings found in reinforced concrete architecture, which is generally scanty and poorly reinforced due to the high import cost of construction steel. The geography of Nepal has led to the development of a wide variety of vernacular architecture using local materials such as stone, brick or earth in the form of rammed earth and adobe walls [1]. Moreover, although its tradition in the construction of vaults is not as prominent as in neighbouring regions of India, Nepal has developed its own tradition in the construction of vaults and domes, which are generally self-supporting and made of brick or adobe with lime mortar. The design of a prototype of seismic house in Nepal aims to use a modular housing unit with rammed earth walls and/or walls made of materials recycled from previous earthquakes, as well as tile vaults with bamboo sleepers, and possibly vegetable fibre grids. These avoid the use of imported materials, favouring $\mathrm{km0}$ and sustainable materials while following local tradition. Several potential housing units have undergone linear seismic analysis on finite element models, with variations in planimetric layout and the types of tile vault, from the simpler barrel vault to the sail vault. Both are analysed searching for the best shape in terms of seismic efficiency, evaluating stress and strain state. The results obtained from this preliminary study clearly show that, under seismic actions, the response from the construction system using depressed sail vaults and rammed earth walls with bamboo reinforcements is more efficient and homogeneous in terms of tension and deformation. This is due to the geometric symmetry which determines the same response in several directions, unlike vaults with a characteristically strong directionality (barrel vault). The seismic response of the prototype described is examined by assessing the influence in terms of thrust and deformation of bamboo reinforcements inside the walls. For this, laboratory tests are used to identify the mechanical characteristics of bamboo to be employed in the finite element modelling and calculation, as the values found in the literature vary depending on the physical and chemical characteristics of the material. This study therefore proposes a more sustainable architectural model with greater antiseismic resistance, always in keeping with local constructive tradition.
\end{abstract}




\section{INTRODUCTION}

The project of an antiseismic dwelling in Nepal aims to merge the characteristics and needs of an antiseismic structure with the architectural tradition of Nepal. The damage caused by the earthquake has steered design towards a modernization of the vernacular architecture, reproducing Western architecture and using reinforced concrete structures. However, these are unsustainable both in environmental and economic terms, given high construction costs. The design of a housing unit prototype is proposed in order to return to the language of vernacular architecture using local materials, but avoiding wood which has become considerably more expensive following the implementation of anti-deforestation legislation. Therefore, a prototype of a dwelling with rammed-earth walls and bamboo reinforcements has been studied. The rammed earth technique, which compacts the soil in formwork using a rammer, is a highly sustainable practice already widespread in Nepal. This technique has been largely researched in the last two decades due to its properties, including good hygrothermal behaviour and low embodied energy. Numerous studies have been carried out on its mechanical characteristics [2-9], seismic assessment [10-12] and energy efficiency [13,14]. The use of structural elements in bamboo (Bambusa Balcooa), plentiful in the region, was decided in order to overcome the shortage of wood. Different studies have also been carried out on the physical and mechanical properties of bamboo [16-23] and its application in rammed earth structures $[24,25]$. The slabs are to be made of tile vaults, which are increasingly gaining international recognition for their durability, economy and ease of

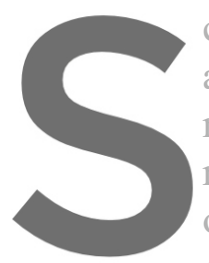
construction, as they analysed before the prot no fibre grid reinforc reflects this first stud. of this vault with the experiences in the field $[30,31]$.
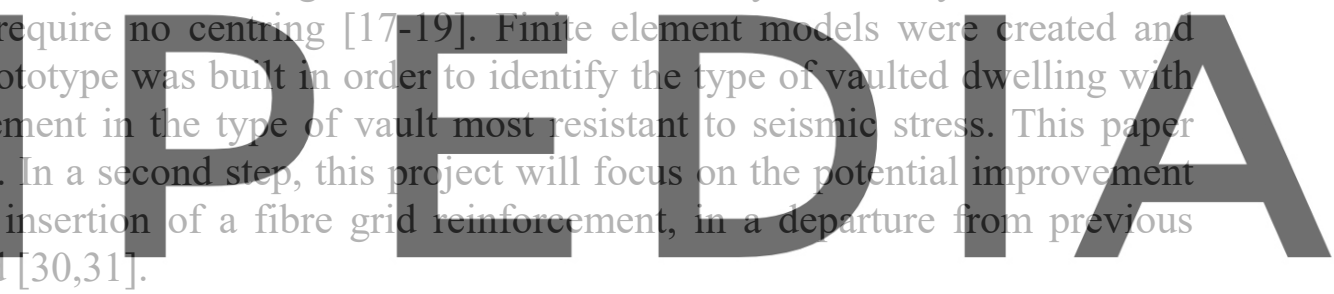

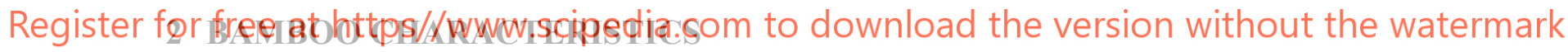

In Nepal, bamboo is the natural material most widely used for different purposes, such as the production of tools or the manufacturing of construction elements. As a construction material, bamboo offers many advantages, as it is sustainable and easily renewable, with mechanical properties comparable to timber. One of the main advantages to bamboo is its rapid growth, which means it can also be widely used in areas where there is a shortage of wood for construction, as in Nepal, where the exploitation of forests has been restricted to prevent deforestation [24]. Furthermore, although bamboo is a type of woody grass and not a tree, bamboo forests display similar characteristics to tree forests in terms of their contribution to the carbon cycle, as bamboo retains carbon in its fibres and soil through photosynthesis [25]. Bamboo is part of the Bambusoideae grass family and its cellulose fibres, about $2 \mathrm{~mm}$ long with an average diameter of $20 \mu \mathrm{m}$, are immersed in a wooden matrix. The number of bundles of fibres and their scattering inside the bamboo culm affect the hardness of the bamboo [26]. In order to evaluate the potential use of bamboo ties in the prototype walls, the tensile strength of the bamboo (Bambusa Balcooa) samples taken in situ was assessed through laboratory tests. 
Given the limited availability of specimens due to the distance from the site, these tests were conducted to compare the tensile strength of the specimens with the values found in literature [21-23], thus selecting proper values for the analysis.

Laboratory tests were carried out on three specimens from a bamboo culm from the Bambusa Balcooa species obtained in situ (Fig. 1). Three specimens of different widths and $9.5 \mathrm{~mm}$ thick were obtained eliminating the outer skin of the culm to obtain a smooth regular surface (Fig. 2). The first standard specimen [27] has a 20x9.5mm shaped section in the useful segment; the second has a rectangular section of $25 \times 9.5 \mathrm{~mm}$, and the third a rectangular section of $50 \times 9.5 \mathrm{~mm}$.

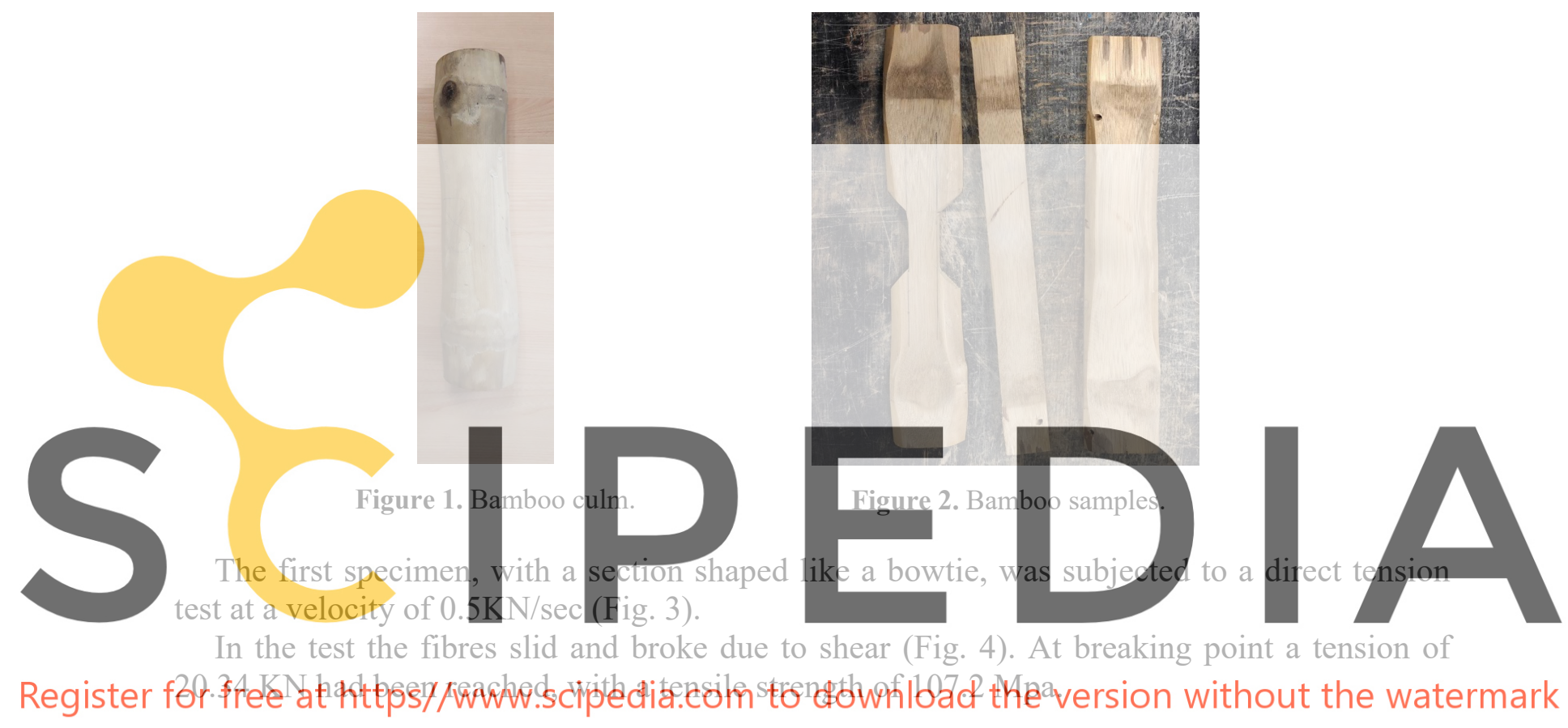

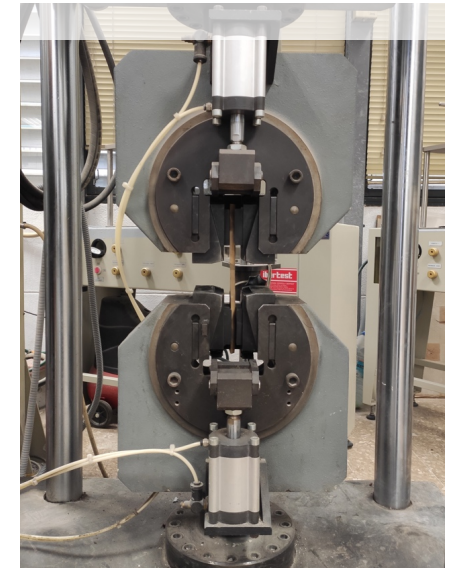

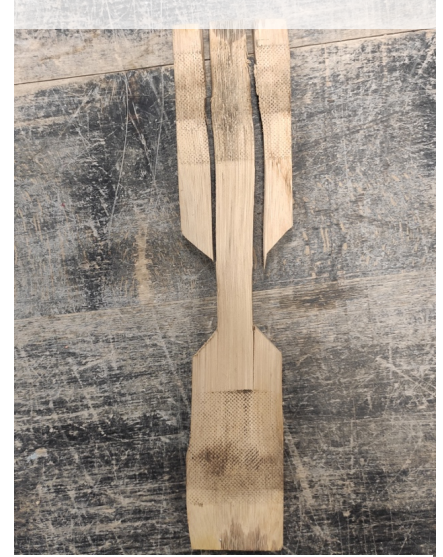

Figure 3. Traction equipment. Figure 4. First specimen after the break.
Tabie 1. Stress trend. First specimen

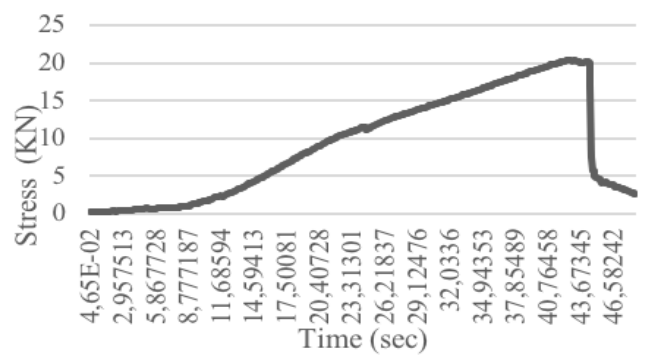


The second direct tension test was carried out on the specimen with a 50x9.5mm rectangular section. Under the same tensile velocity as that of the first test a break was also observed due to the compression of the ties at the end (Fig. 5). The tension recorded at breaking point was $39.10 \mathrm{KN}$ and tensile strength was $82 \mathrm{Mpa}$.

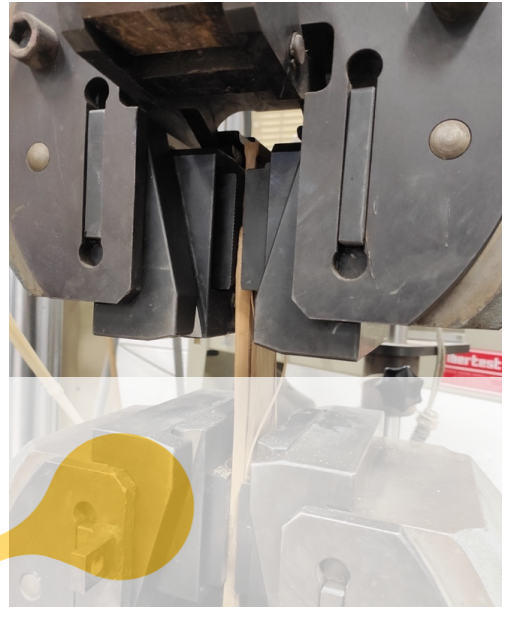

Figure 5. Second specimen
Table 2. Stress trend. Second specimen

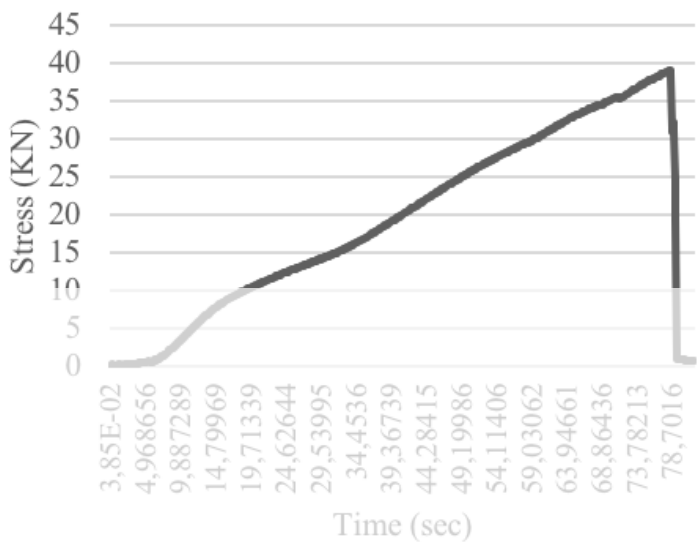

Finally, a bending test section in order to indir during the test. The specimen

$\mathrm{mm} / \mathrm{min}$, until the inne point was $118.9 \mathrm{MPa}$ and, considering that the
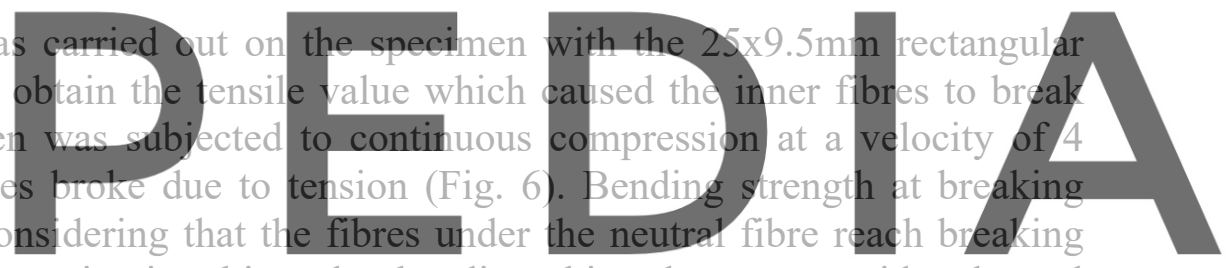
point due to tension when the section is subjected to bending, this value was considered equal

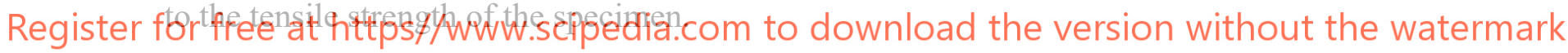

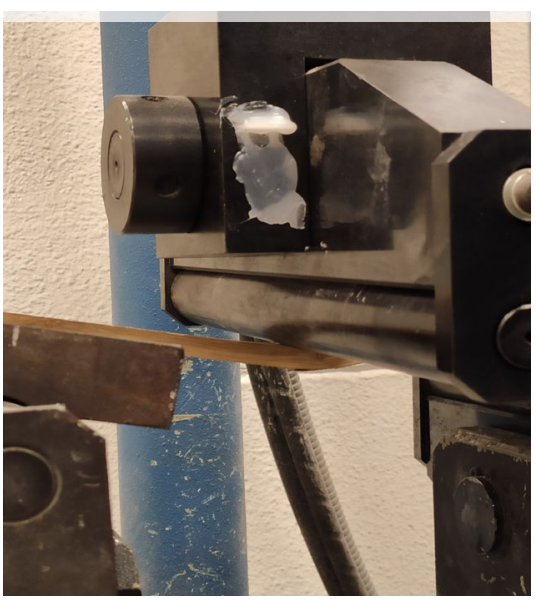

Table 3: Stress-strain trend - Third specimen

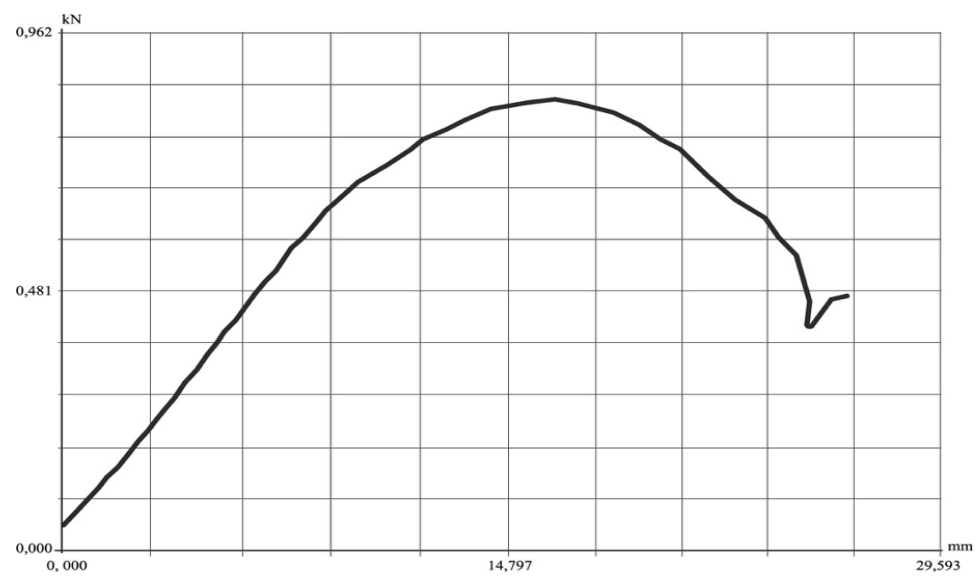

Figure 6. Rupture of the fibres of the third specimen. 
The mean tensile strength value is $102.7 \mathrm{Mpa}$. This value should be considered a minimum tensile strength value as not all specimens broke due to the tension of fibres, but because of shear or the pressure of the ties.

Given the difficulties in accessing the location to obtain specimens the number of tests carried out may not be enough to obtain a population of values to define the characteristic tensile strength value. Thanks to the tests carried it was verified that the values obtained are within the range of values found in specialist literature [21-23]. Therefore, it was considered necessary to use the characteristic tensile strength values and other mechanical characteristics of bamboo as detailed by Kaminski et al. (2016), considered valid for all the species in the scheme design phase for buildings with smaller floor plans and elevations.

\section{CONCEPTUAL DESIGN OF THE PROTOTYPE}

Preliminary analysis with the finite element method was crucial to the definition of the type and shape of the vault to be used, given the extreme vulnerability of vaulted structures to drift. When executing a finite element analysis, the materials must be exactly defined. In this case, given the lack of experimental data, the mechanical properties considered for simple rammed earth are those found in the literature [4-9], reported in Table 4.

Table 4. Rammed earth mechanical properties in the literature

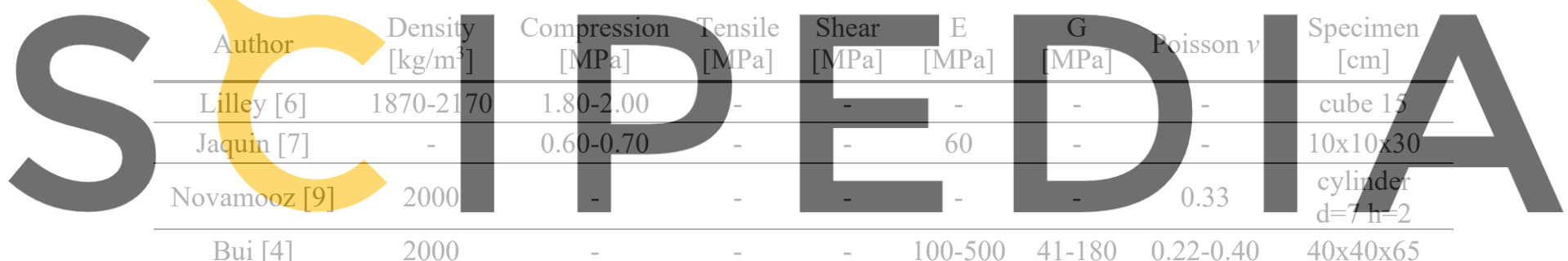

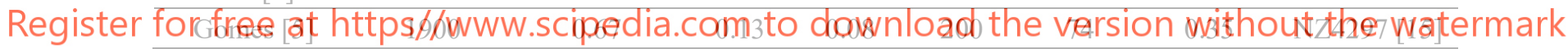

The mechanical properties for rammed earth and bamboo used for FE analysis are shown in Table 5 and Table 6.

Table 5. Rammed earth mechanical properties used for the models.

\begin{tabular}{cccc}
$\begin{array}{c}\mathrm{E} \\
{[\mathrm{MPa}]}\end{array}$ & $\begin{array}{c}\text { Compression } \\
{[\mathrm{Mpa}]}\end{array}$ & $\begin{array}{c}\text { Tensile } \\
{[\mathrm{Mpa}]}\end{array}$ & $\begin{array}{c}\text { Density } \\
{\left[\mathrm{kg} / \mathrm{m}^{3}\right]}\end{array}$ \\
\hline 250 & 2.00 & 0.20 & 2000 \\
\hline
\end{tabular}

${ }^{\circ}$ Table 6. Bamboo mechanical properties used for the models.

\begin{tabular}{cccccc} 
Author & $\begin{array}{c}\mathrm{E} \\
{[\mathrm{MPa}]}\end{array}$ & $\begin{array}{c}\text { Compression } \\
{[\mathrm{Mpa}]}\end{array}$ & $\begin{array}{c}\text { Tensile } \\
{[\mathrm{Mpa}]}\end{array}$ & $\begin{array}{c}\text { Flexure } \\
{[\mathrm{Mpa}]}\end{array}$ & $\begin{array}{c}\text { Shear } \\
{[\mathrm{Mpa}]}\end{array}$ \\
\hline Kaminski et al. [21] & 17000 & 20 & 40 & 30 & 2 \\
\hline
\end{tabular}


Linear seismic analysis on finite element models was carried out on several prototypes of housing units with different plans and tile vault types, from simple barrel vaults (Fig. 7) to pendentive domes or sail vaults (Fig. 8). This assumed different values for the height of the springer, rise and thickness, evaluating the tensile and deformative state, in order to establish the best overall shape in terms of seismic efficiency. Since this is a preliminary analysis, no non-linear analysis was carried out due to the highly variable data and computational difficulty.

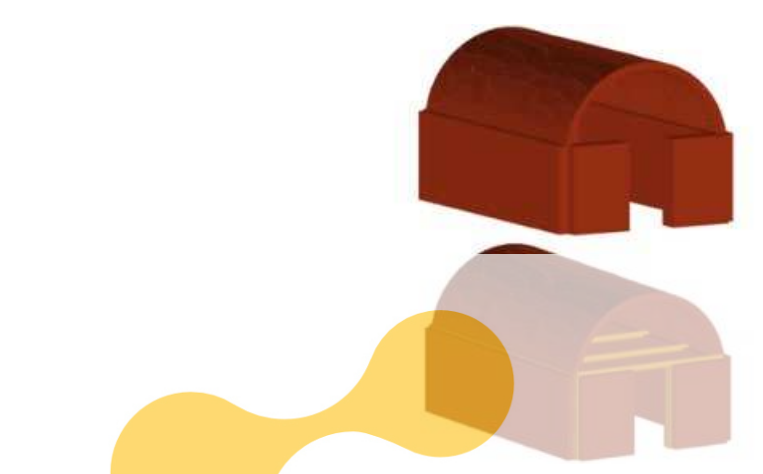

Figure 7. Models with barrel vault.
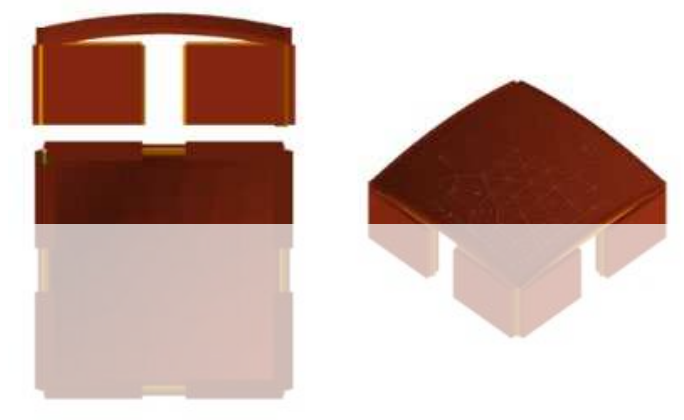

Figure 8. Model with pendentive dome.

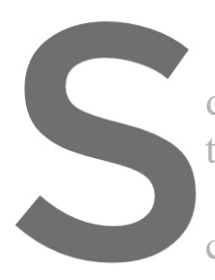

Rammed earth walls defined by three and four three components of tra

In addition, bamboo consisting of three translation
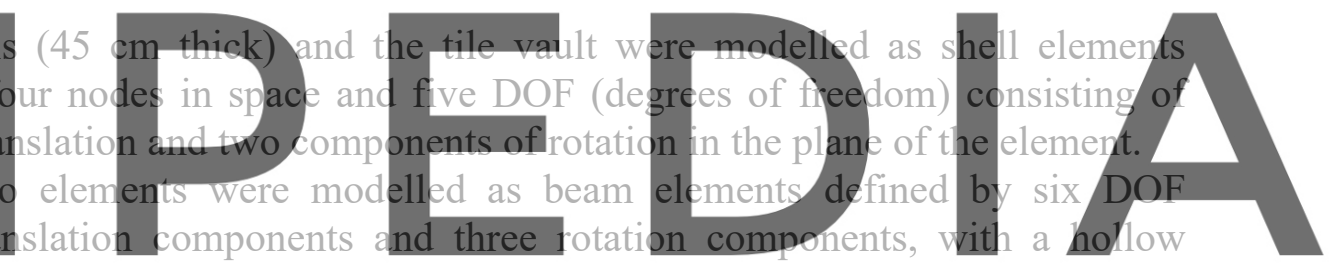

section with a $7.5 \mathrm{~cm}$ external radius and $6 \mathrm{~cm}$ internal radius.

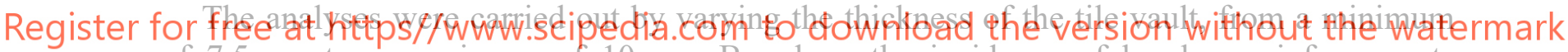
of $7.5 \mathrm{~cm}$ to a maximum of $10 \mathrm{~cm}$. Based on the incidence of bamboo reinforcements assessed for the individual models it can be stated that, regardless of the shape considered, the value of displacements significantly decreased when ties were used, improving seismic response (Fig. 10).

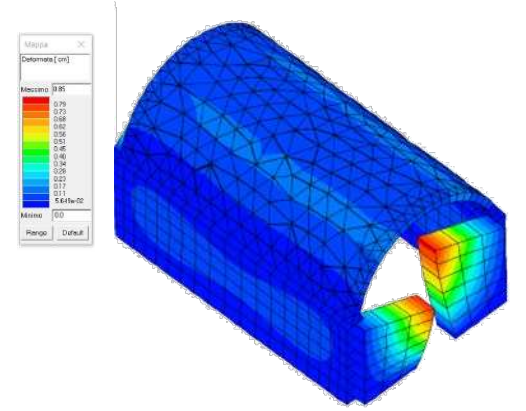

Figure 9. Deformation. Fifth mode. Unreinforced model.

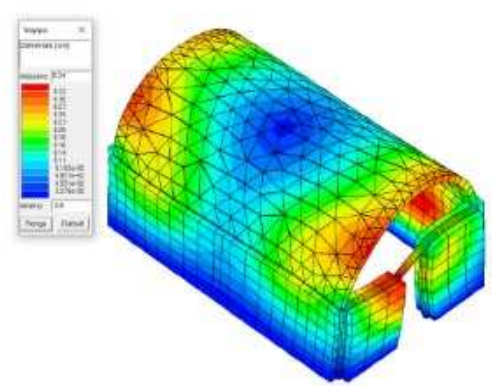

Figure 10. Deformation. Fifth mode. Reinforced model. 
The 2015 Gorkha earthquake had a magnitude $\mathrm{Mw}$ of 7.8, $15 \mathrm{~km}$ deep, the recorded maximum PGA was $\sim 0.25 \mathrm{~g}$. The design PGA recommended by the Nepal building codes is $0.36 g$ (NBC-105, 1994). Based on the previous data, the acceleration response spectrum shown in Table 7 was considered.

Table 7. Design acceleration response spectrum

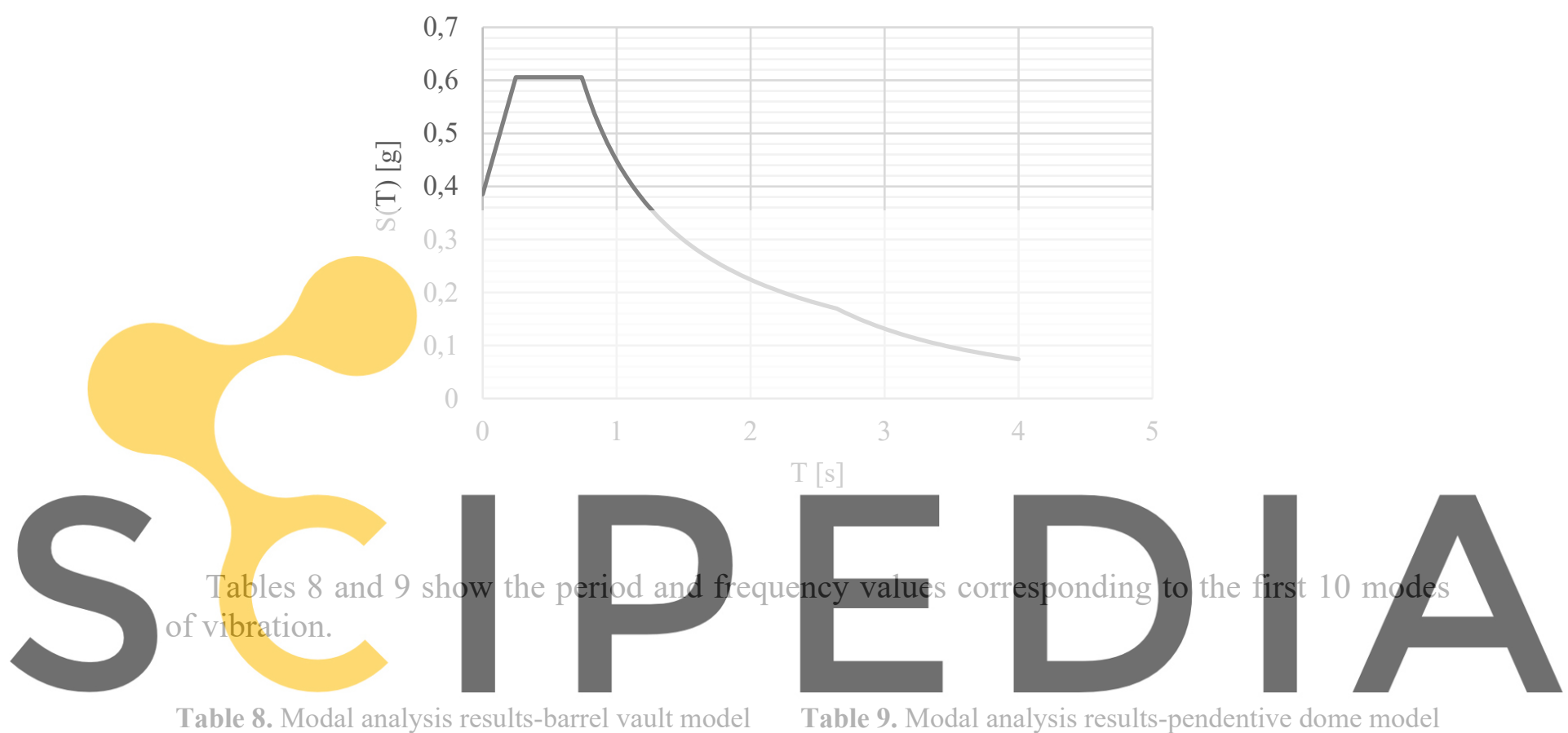

Register for free at https//www.scipedia.com to download the version without the watermark

\begin{tabular}{ccc}
\hline Modes & Frequency & Period \\
\hline 1 & 6.81 & 0.15 \\
\hline 2 & 15.63 & 0.06 \\
\hline 3 & 15.98 & 0.06 \\
\hline 4 & 16.42 & 0.06 \\
\hline 5 & 20.02 & 0.05 \\
\hline 6 & 21.22 & 0.05 \\
\hline 7 & 21.66 & 0.05 \\
\hline 8 & 25.58 & 0.04 \\
\hline 9 & 25.70 & 0.04 \\
\hline 10 & 28.36 & 0.04 \\
\hline
\end{tabular}

\begin{tabular}{ccc}
\hline Modes & Frequency & Period \\
\hline 1 & 7.32 & 0.14 \\
\hline 2 & 8.77 & 0.11 \\
\hline 3 & 8.77 & 0.11 \\
\hline 4 & 9.02 & 0.11 \\
\hline 5 & 9.43 & 0.11 \\
\hline 6 & 9.91 & 0.10 \\
\hline 7 & 11.14 & 0.09 \\
\hline 8 & 11.16 & 0.09 \\
\hline 9 & 14.02 & 0.07 \\
\hline 10 & 14.10 & 0.07 \\
\hline
\end{tabular}

To better understand the seismic behaviour of the models, it is useful to observe the major difference in behaviour between a simpler vault such as the barrel vault and the pendentive dome. The seismic response of the barrel vault model is poorer than that of the model with a pendentive dome. In fact, the deformation and the tensional state of a barrel vault are 
noticeably influenced in the direction of the earthquake, giving rise to greater deformation if orthogonal to the direction of the axis. In addition, tensile stresses appear in the entire structure which could lead to collapse. In Fig. 13 and Fig. 14, only tensions are highlighted, in order to reflect the peak reached when the seism is orthogonal to the axis, with a maximum value of $6.95 \mathrm{daN} / \mathrm{cm}^{2}$. In contrast, the response of the model with a pendentive vault is not significantly affected by the direction of the earthquake, and the final deformation appears more homogeneous. Likewise, the tensional state of this model is less critical, considering the decrease of the tensile stresses, with a maximum of $2.12 \mathrm{daN} / \mathrm{cm}^{2}$.

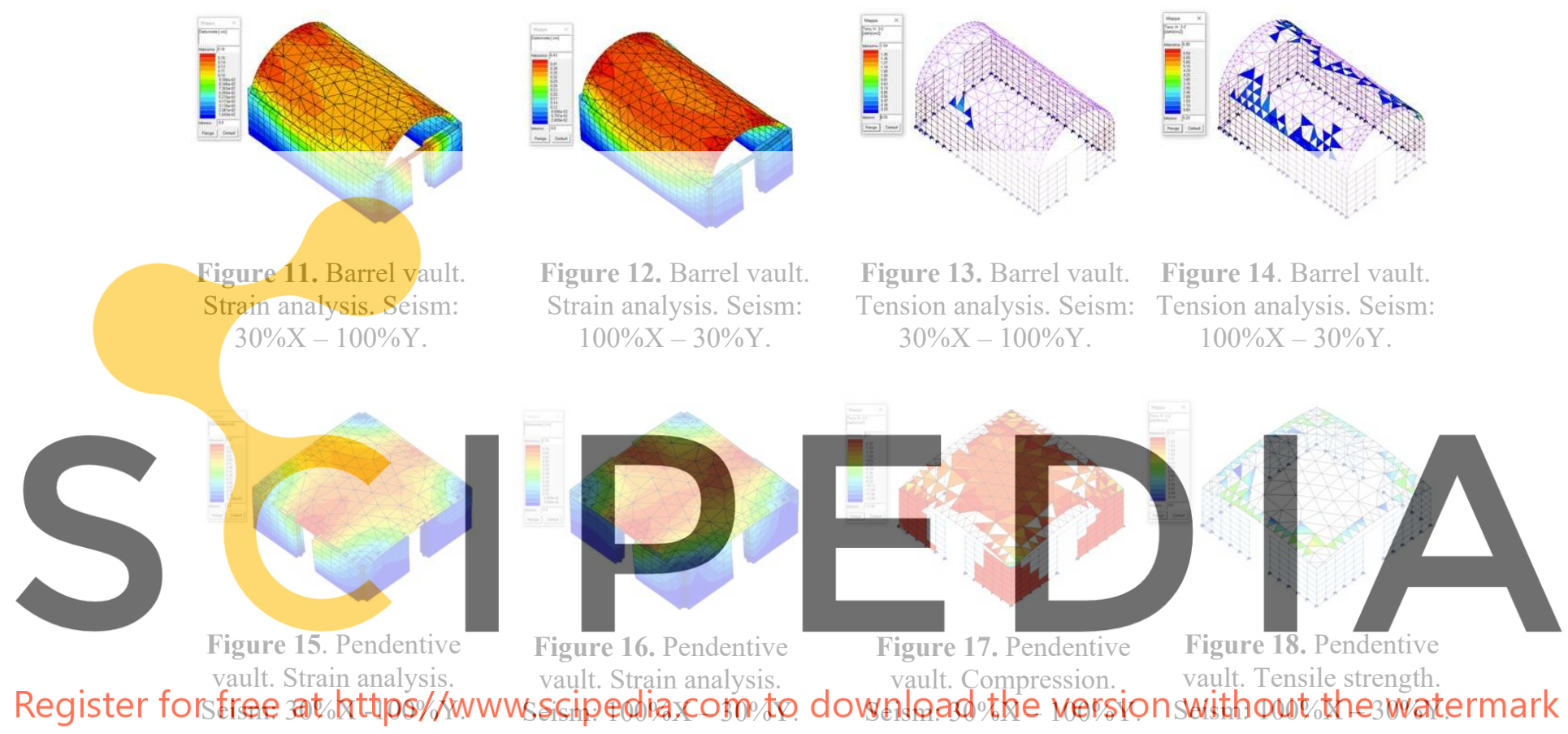

4 CONCLUSIONS

Preliminary analysis of the models made it possible to identify the advantages and weaknesses of the recovered construction system, in order to move forward with a design which preserves traditional construction techniques while resisting seismic events, through the use of ties. Bamboo ties were inserted in order to ensure maximum sustainability for the project. It should be noted that tensile rupture of the test piece was not reached in any of the cases, and therefore the resistance values obtained should be considered to be minimum. Finally, the HouSe-Nepal project is imbued with the general spirit of the project of an antiseismic housing module born from the reinterpretation of vernacular architecture, better adapted to the environment both in terms of architecture and materials, and in terms of social and economic impact. The dwelling modules and the construction techniques presented in this paper are preliminary approaches to the design of a sustainable antiseismic dwelling in Nepal trying to provide an alternative for Nepalese dwellings which are currently being built with industrial materials such as cement blocks and metal sheets, which often generate unhealthy spaces. 
Acknowledgements. This work is part of the research project "HouSe-Nepal. Prototype for a sustainable anti-Seismic dwelling in Nepal", funded by the Centre for the Cooperation to Sustainability of the Universitat Politècnica de València (main researcher: Fernando Vegas López-Manzanares).

\section{REFERENCES}

[1] CBS 2014, Annual household survey. Gov.Nepal. Katmandú (2014).

[2] Bui, T.T., Bui, Q.B., Limam, A., Maximilien, S. Failure of rammed earth walls: From observations to quantifications. Constr. and Building Materials (2014) 51: 295-302.

[3] Bui, T.T., Bui, Q.B., Limam, A., Morel, J.C. Modeling rammed earth wall using discrete element method. Continuum Mech. Thermodyn. (2016) 28:523-538.

[4] Bui, Q. B., Morel, J., Hans, S., Meunier, N. Compression behaviour of non-industrial materials in civil engineering by three scale experiments: The case of rammed earth. Materials and Structures/Materiaux et Constructions (2009) 42(8): 1101-1116.

[5] Gomes, M.I., Lopes, M. And De Brito, J. Seismic resistance of earth construction in Portugal. Engineering Structures (2011) 33(3): 932-941.

[6] Lilley D.M., Robinson J. Ultimate strength of rammed earth walls with openings. In: Proceedings of the Inst. of Civil Eng. - Struc. and Buildings (1995) 110(3): 278 - 287.

[7] Jaquin P. A., Augarde C.E., Gerrard C.M. Analysis of historic rammed earth construction. In: Structural anatysis of historical constructions, New Deini (2006).
Miccoli, L., Drougkas, A., Müller, J. In-plane behavior of ramned earth under cyclic
loading: Experimental testing and finite element modelling. Eng. Struct. (2016) $\mathbf{1 2 5}$ :
144-152.
Nowamooz, H., Chazallon, C. Finite element modelling of a yammed earth yall.
Construction and Building Materials (2010) $25(4): 2112-2121$.

Construction and Building Materials (2010) 25(4): 2112-2121.
[10] Bui, Q.B.; Bui, T.T.; Limam, A. Assessing the seismic performance of rammed earth

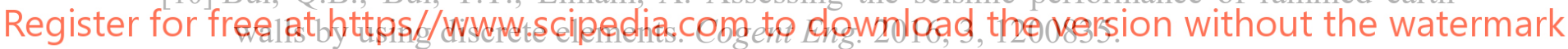

[11] Liu K, Wang YA, Wang M. Experimental and numerical study of enhancing the seismic behavior of rammed earth buildings. In: Advanced Materials Research Vols 919-921 (2014) pp. 925-931.

[12] El-Nabouch R., Bui Q.B., Plé O., Perrotin P. Assessing the in-plane seismic performance of rammed earth walls by using horizontal loading tests, Engineering Structures, (2017) 145: $153-161$.

[13] Allinson, D., Hall, M. Hygrothermal analysis of a stabilized rammed earth test building in the UK. Energy and Buildings (2010) 42: 845-852.

[14] Soudani, L., Fabbri, A. Morel, J.C. Assessment of the validity of some common assumptions in hygrothermal modelling of earth-based materials. Energy and Building (2016) 116: 498-511.

[15] NZ 4297. 1998 Engineering design of earth buildings. New Zealand: Earth Building. Association of New Zealand.

[16] Maldonado Ramos, L., Castilla Pascual F. J., Vela Cossio F. La técnica del tapial en la Comunidad Autónoma de Madrid. Aplicación de nuevos materiales para la consolidación de muros de tapia. Informes de la construcción (1997) Vol. 49 452: 27-37. 
[17] Ramage, M., Ochsendorf, J., Rich, P. Sustainable shells: New African vaults built with soil-cement tiles. Journal of the IASS (2010, December) Vol. 51(4): 255-261.

[18] Block, P., DeJong, M., Davis, L., Ochsendorf, J. Tile vaulted systems for low-cost construction in Africa. Journal of the African Technology Development Forum (ATDF) - Special Issue on Architecture for Development (2010) 7: 4-13.

[19] Block, P., Van Mele, T., \& Rippmann, M. Structural Stone Surfaces: New Compression Shells Inspired by the Past. Architectural Design (2015) 85(5): 74-79.

[20] Bhattacharya, S., Ghosh, J.S., Sahoo, D. K., Dey N., Pal A. Screening of superior fiberquality-traits among wild accessions of Bambusa balcooa: efficient and non-invasive evaluation of fiber developmental stages. Annals of Forest Science, Springer Verlag/EDP Sciences (2010) 67 (6).

[21] Kaminski, S., Lawrence, A., Trujillo, D., Feltham, I., Lopez, L.F. Structural use of bamboo. Part 3: Design values. Structural Engineer (2016) 94 (12).

[22] Sanchez Vivas, L., Mullins, G., Cunningham, J. A., Mihelcic, J. R. Mechanical properties of bamboo: a research synthesis of strength values and the factors influencing them. Journal of American Bamboo Society (2019, October) 29(7): 1-22.

[23] Awalluddin, D., Ariffin, M. A., Osman, M., Hussin, M., Ismail, M., Lee, H., Abdul S. L., Nor H. Mechanical properties of different bamboo species. MATEC Web of Conferences (2017) 138: 01024.

[24] Sharma, B., Gatóo, A., Bock, M. and Ramage, M. Engineered bamboo for structural applications. In: Construction and Building Materials (2015) 81:66-73.

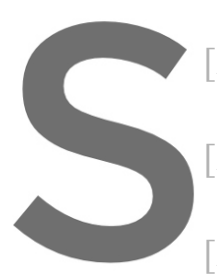

25] Yiping, L., Yanxia Change Mitigation

26] Seema Jain, R. K In: Journal of Mater
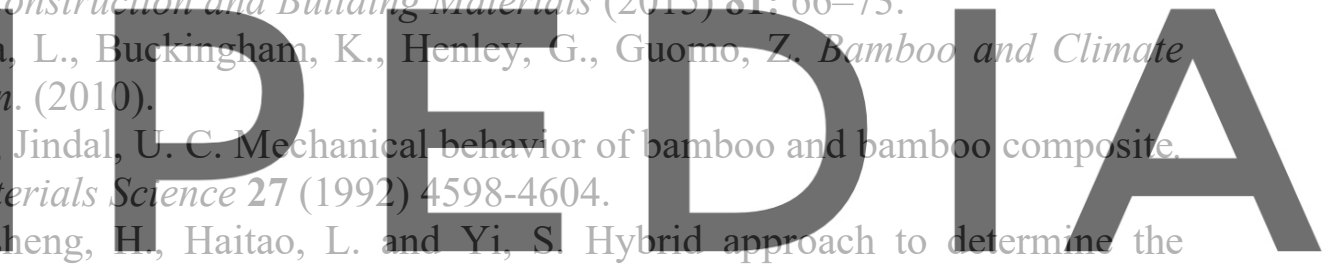
mechanical parameters of fibers and matrixes of bamboo. Construction and Building

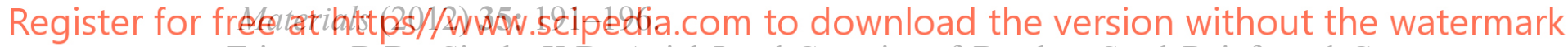

[28] Tripura, D.D., Singh, K.D. Axial Load-Capacity of Bamboo-Steel Reinforced Cement Stabilised Rammed Earth Columns. Struc. Engineering International. (2016) 29 (10).

[29] Tripura, D.D, Singh, K.D. Mechanical behaviour of rammed earth column: a comparison between unreinforced, steel and bamboo reinforced columns. Materiales de Construcción (2018) 68 (332) 174.

[30] DeJong, M.J., Ramage, M.H., Travers, B., Terry, S. Testing and analysis of geogridreinforced thin-shell masonry. In Proceedings of the IABSE-IASS Symposium, London (2011, September).

[31] Ramage, M.H., DeJong, M.J. Design and construction of geogrid-reinforced thin-shell masonry. In Proceedings of the IABSE-IASS Symposium, London (2011, September).

[32] Nepal Building Codes (NBC-105). Seismic design of buildings in Nepal. Dep. of Urban Dev. and Buil. Constr. Min. of Housing and Physical Planning, Gov. of Nepal (1994). 